\title{
Study of Vulnerability to Addiction With Regard to Self- Efficacy and Alexithymia in High School Students
}

\author{
Farhad Ghadiri Sourman Abadi ${ }^{\text {* }}$, Karim Abdolmohamadi², Jalil Babapur Kheiradin ${ }^{1}$, Ezatolah Ahmadi \\ 1. Department of Psychology, Faculty of Education and Psychology, University of Tabriz, Tabriz, Iran. \\ 2. Department of Exceptional Children Psychology, Faculty of Psychology \& Education, Allameh Tabataba'i University, Tehran, Iran. \\ 3. Department of Psychology, Faculty of Education and Psychology, Azarbaijan Shahid Madani University, Tabriz, Iran.
}

Cltation: Ghadiri Sourman Abadi, F., Abdolmohamadi, K., Babapur Kheiradin, J., Ahmadi, E. (2016). Study of Vulnerability to Addiction With Regard to Self-Efficacy and Alexithymia in High School Students. Journal of Practice in Clinical Psychology, 4(4), 221-228. https://doi. org/10.18869/acadpub.jpcp.4.4.221

: https://doi.org/10.18869/acadpub.jpcp.4.4.221

\section{Article info:}

Received: 30 Apr. 2016

Accepted: 28 Jul. 2016

\section{Keywords:}

Addiction, Self-efficacy, Alexithymia, Vulnerability to addiction

\begin{abstract}
A B STRACT
Objective: We aimed to determine the relationship between self-efficacy and alexithymia with vulnerability to drug abuse among students.

Methods: The study method was descriptive and correlational. In this study, 483 male highschool students from Salmas City, Iran were selected by multi-stage cluster sampling method. All participants completed the Toronto alexithymia scale, general self-efficacy scale, a questionnaire to identify people at risk of addiction. The obtained data were analyzed using the Pearson correlation and simultaneous regression analysis. Statistical analysis was performed using SPSS 20.
\end{abstract}

Results: Based on the study findings, self-efficacy has the greatest ability to predict vulnerability to addiction. Next comes alexithymia which positively predicts vulnerability to addiction.

Conclusion: The present study showed that low self-efficacy and failure to understand and express emotions can play important roles in the tendency of young people to drug addiction. Accordingly, clinicians can prevent the tendency of young people to addiction with improving the self-efficacy and enhancing the ability of individuals to control the emotions.

\section{Introduction}

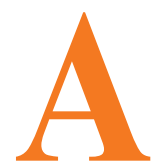

ddiction is one of the most sensitive social issues that threatens the whole community, especially the younger generation (Karkhi, 2012). Today, drug addiction is a global problem. Currently, there are 218 million addicted people around the world. Our country neighbors major areas of drug production and is located in the shortest transit route, which leads to the complexity of drug trafficking. In spite of several measures taken in this re- gard, addiction has spread in various social groups, especially among young people. There are 1200000 drug users and 800000 recreational consumers in Iran, which makes it a major threat that eventually leads to family breakdown and other serious problems (Amani et al., 2005).

Addiction and substance abuse as a social problem has the potential to destroy social organizations and order. It also causes structural changes in the economic, social, political, and cultural aspects of a society. The World Health Organization (WHO) considers the issue of drugs, includ-

\footnotetext{
* Corresponding Author:

Farhad Ghadiri Sourman Abadi, MA

Address: Department of Psychology, Faculty of Education and Psychology, University of Tabriz, Tabriz, Iran.

Tel: +98 (914) 1879410

E-mail:farhadghadiri17@yahoo.com
} 
ing production, transmission, distribution, and consumption as a fundamental issue and as important as the three other global problems: production and stockpiling of weapons of mass destruction; pollution; poverty and class differences (WHO,1999, cited in Bagheri et al., 2011). Adolescents are not immune to the risk of addiction. According to the reports in 2003, the age of drug onset use has risen from 14 to 16 years in Iran, which demands a lot of research on the causes and rates of drug use among adolescents (Dehkordian, Delavar, and Jali, 2011).

Literature review reveals that substance and alcohol abuse is prevalent among adolescents. They pass through a developmental period with a lot of physical and emotional changes that make them vulnerable to drug abuse (Thatcher \& Clark, 2008, cited in Dolatshahi, Abasi, Pahlavani, 2016). Most people who work with adolescents have noticed that they take refuge in drugs, which is a response to their repeated exposures to inappropriate situations, including feelings of insecurity, stress, psychological distress, and conflict with parents or problems of everyday life. In many people, drug abuse begins at high-school age. Thus, one way to reduce drug use in adulthood, is its control in adolescence period (Tavousi et al., 2011). Because the onset of drug use is declining and it is focused on students, identifying variables associated with addiction in this sensitive period, is very important.

Self-efficacy is one of the variables that is associated with substance abuse. It includes individual judgments about the ability to carry out specific tasks (Schultz and Schultz, 2000). Self-efficacy refers to people's trust in their abilities to follow a behavior and overcome the barriers to achieve it (Saffari, Shojaizaseh, \& Ghofranipour, 2009, cited in Hatami et al., 2016).

In his cognitive-social theory, Bandura (1993), by invoking the concept of self-efficacy on person's perception, focused on personal effectiveness as a cognitive mediator, i.e., when humans perform an action, judge about their abilities and competencies, and these judgments affect their minds, emotions, and behaviors.

Dolan and White (2008) reported that there was an inverse relationship between high levels of self-efficacy and the desire to use drugs in high-risk situations. Mckellar et al. (2008) also demonstrated that the rate of self-efficacy in the first year of recovery was a good predictor for depression, arousal, alcohol reduction, problems associated with alcoholism, social support from friends, and longterm participation in Alcoholics Anonymous program.
Mohammadkhani et al. (2007) in a study on the adolescents at risk in Tehran, concluded that factors such as locus of control and self-control skills impact substance use in adolescents. These factors work via the individual and community empowerment. The results of Tate and colleagues (2008) showed that poor self-efficacy provides the ground for substance abuse in adolescents and young adults.

One of the other psychological factors associated with substance abuse is alexithymia. Alexithymia is a known emotional disorder. The term alexithymia was coined in 1973 by Sifneos and derived from the Greek root of Alexi (lack of words) and thymus (emotion) and show an inability to express emotions (Lesser, 1985, cited in Ghadiri et al., 2015). The patients with alexithymia have four characteristics: problem in recognizing and describing feelings, problem in distinguishing feelings from physical sensations, lack of the ability for imagination and symbolic thought, and tendency to thinking and problem-solving objectively (Humpfries, Wood, \& Parker, 2009, cited in Ameri, Bayat, Kosravi, 2014).

People with this trait have problems in understanding the emotional states of others, in interpersonal relationships, and demonstrate limited empathy (Berenbaum, \& Prince, 1994; Hashemi et al., 2013).

The study results have shown that alexithymia is a risk factor for mental and physical disorders (Tylor et al., 1997; cited in Besharat, Nourbakhsh, Rostami, 2014). Alexithymia is associated with alcohol consumption and alcohol use disorders (Birt et al., 2008; Thorberg et al., 2009; De Rick and Vanheule, 2006). About 45\% to 67\% of alcohol consumers have shown symptoms of alexithymia (Evren et al., 2008; Laos et al., 1997).

A study on the addicted men in Egypt showed that people who took several substances were more prone to alexithymia than people who took one drug (Rasheed, 2001). Also the results of several studies have confirmed the positive relationship between alexithymia and severity of alcohol use disorder (Cecero and Holmstrom, 1997; Haviland et al., 1988).

The prevalence of addiction to drugs, especially in adolescents and young adults indicate that the young generation who should participate in the development and progress of society, is wasted in the trap of addiction. Therefore, it is necessary to conduct, broad and in-depth studies to identify factors underlying addiction. Although in recent years, some studies have been conducted on drug addicts, few studies are found in the field of alexithymia and self-efficacy that are predictors of ad- 
diction. For this reason, this study was designed to examine and predict the vulnerability to addiction on the basis of self-efficacy and alexithymia in high-school students.

\section{Methods}

This research method was descriptive and correlational. The study population comprised all male high-school students in Salmas City, Iran, including 7652 students who were enrolled in 2014-2015 academic year. The sample size on the basis of Krejcie and Morgan Table ( $\mathrm{N}=8000)$ was estimated as 367 people. Population size was rounded to 8000 , but considering some loss of participants (incomplete questionnaires), the size sample was taken of 500, which were selected by multi-stage cluster sampling method. In this way, at first, among 20 boys' high-schools of Salmas, 5 high-schools were selected by cluster random sampling method.

In each school, 25 students per class and a total of 100 students were randomly selected. Thus in total, $500 \mathrm{stu}-$ dents completed questionnaires. Of those, 17 students were excluded from the study due to flaws in their questionnaires and the final sample was reduced to 483 people. It should be noted the age range of the participants was 15 to 19 years. Also, volunteers who participated in the study were free to terminate their collaboration at any time for any reason.

After explaining the purpose of the study and invoking students' participation and confidence, Toronto alexithymia scale (TAS-20), the general self-efficacy scale, and the questionnaire to identify people at risk of addiction, were administered to them. The obtained data were analyzed using the Pearson correlation and simultaneous regression analysis. Statistical analysis was performed using SPSS 20.

Anisi questionnaire to identify people at risk of addiction: This questionnaire is a screening tool that was designed in 2013 by Jaafar Anisi at Baqiyatallah University of Medical Sciences. The questionnaire consists of 75 items and 4 subscales; The subscales are as 1) Depression and helplessness, 2) Positive attitude to drugs, and 3) Anxiety and fear of others, and high sensation seeking.

Scoring is done on 4-point Likert-type scale from totally disagree (0), disagree (1), somewhat agree (2), and agree (3). Scores range from 0 to 225 and the cutoff point of the test is 80 . In other words, people who have a score of 80 or higher are at risk of addiction. Cronbach $\alpha$ for this scale has been reported at 0.97 (Ghadiri, Sabouri, Babapour, 2014).
Toronto Alexithymia Scale: It is a 20 -question test and measures 3 subscales of difficulty in identifying feelings, difficulty in describing feelings, and externally oriented thinking with a 5-point scale (Score 1 for strongly disagree and 5 for strongly agree). Total score is calculated as the sum of 3 subscale scores for alexithymia (Bagby, Parker, and Tylor, 1994). In Farsi version of the Toronto alexithymia scale (Besharat, 2007), the Cronbach $\alpha$ coefficients were calculated for total alexithymia and its 3 subscales of difficulty in identifying feelings, difficulty in describing feelings, and externally oriented thinking as $0.85,0.82,0.75$, and 0.72 , respectively, indicating good internal consistency of the scales.

General self-efficacy scale: In this study, the Schwarzer's 10-item general self-efficacy scale was used. Nezami, Schwarzer, and Jerusalem (1996) translated the original scale (in German) into Persian. The general self-efficacy scale was created to assess the general sense of perceived self-efficacy to predict coping with daily hassles as well as adaptation after experiencing all kinds of stressful life events. Responses are rated on a 4-point scale (1 to 4).

Summing the responses to all 10 items yields the final composite score with a range from 10 to 40 . Higher scores indicate more levels of perceived general self-efficacy. This scale was based on criterion-related validity and its Cronbach $\alpha$ ranged from 0.76 to 0.90 . This questionnaire has been validated in Iran by Rajabi (2006) and the Cronbach $\alpha$ coefficient has been reported as 0.85

\section{Results}

Table 1 shows data on the basis of the study participants. In the present study, before examining the contribution of predictor variables of vulnerability to addiction in the regression model, the simple correlation between the variables were examined (Table 2). Based on the analysis, vulnerability to addiction has a significant negative relationship with self-efficacy and a significant positive relationship with alexithymia.

Before performing the analysis, initial tests were conducted to ensure no violation of the assumptions of normality, linearity, multiple linear, and same distribution. In this study, to assess the independent predictive variables, multiple linearity assumption was calculated. Tolerance and the variance inflation factor were derived. Tolerance index values were in the range of 0.73 to 0.82 and index variance inflation factor ranged from 1.31 to 1.57. Therefore, it is possible that predictive variables are independent of each other and multiple linear did not happen. After the test and ensuring of no violation of the 
Table 1. The study participants' frequency with respect to their grades.

\begin{tabular}{ccc}
\hline Grade & Frequency & $\%$ \\
\hline First grade & 149 & 30.8 \\
\hline Second grade & 190 & 39.3 \\
\hline Third grade & 144 & 29.8 \\
Total & 483 & 100 \\
\hline
\end{tabular}

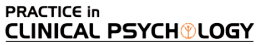

Table 2. Matrix of simple correlation coefficients between self-efficacy, alexithymia, and vulnerability to addiction.

\begin{tabular}{cccccc}
\hline Components & M & SD & Vulnerability to Adiction & Self-efficacy & Alexithymia \\
\hline Vulnerability to addiction & 78 & 34.99 & 1 & & \\
Self-efficacy & 27.62 & 6.51 & $-0.38^{* *}$ & -0.03 & 1 \\
\hline Alexithymia & 55.90 & 9.97 & $0.26^{* *}$ & & 1 \\
\hline
\end{tabular}

** Significant at the $\mathrm{P}<0.01$.

* Significant at the $\mathrm{P}<0.05$.

Table 3. Regression analysis to predict vulnerability to addiction through self-efficacy and alexithymia.

\begin{tabular}{cccccccccccc}
\hline & \multicolumn{10}{c}{ Index } \\
\cline { 2 - 11 } & $\mathbf{B}$ & $\boldsymbol{\beta}$ & $\mathbf{t}$ & $\mathbf{P}$ & $\mathbf{R}$ & $\mathbf{R}^{2}$ & $\mathbf{R}^{2} \boldsymbol{\Delta}$ & $\mathbf{E} . \mathbf{S}$ & $\mathbf{F}$ & $\mathbf{P}$ \\
\hline Model & & & & & 0.45 & 0.20 & 0.19 & 31.23 & 61.66 & 0.001 \\
Self-efficacy & -1.99 & 0.22 & -9.07 & 0.001 & & & & & & \\
Alexithymia & 0.87 & 0.14 & 6.07 & 0.001 & & & & & \\
\hline
\end{tabular}

Predictors: Self-efficacy and alexithymia.

Dependent variable: Vulnerability to addiction.

assumptions, the regression analysis was used to determine which variables predict vulnerability to addiction. Table 3 shows the results of the regression analysis.

Table 3 shows that multiple correlation (MR) for the regression model is 0.45 , its square $\left(R^{2}\right)$ is equal to 0.20 , and the correction coefficient is 0.19 . In other words, $19 \%$ of changes in "vulnerability to addiction" is explained by self-efficacy and alexithymia. Of the two components, self-efficacy can negatively predict the maximum power in vulnerability to addiction.

\section{Discussion}

The study results indicate that alexithymia has a positive and significant relationship with and is a predictor of "vulnerability to addiction." These results agree with the findings of previous studies (Rasheed, 2001; Pinard et al., 1996; Thorberg et al., 2009; Uzun, 2003; Cleland et al., 2005; Besharat, Nourbakhsh, Rostami, 2014).

Regarding the relationship between alexithymia and vulnerability to addiction, we can argue that addictive substances are used to avoid negative emotions and help the person to be away from them (Besharat, Nourbakhsh, Rostami, 2014). Rybakowski et al. (1998) believed that consumption of alcohol could be a way to relieve stressful situations for people with alexithymia. Moreover, consumption of alcohol facilitates emotional and verbal communication of these people, and pleasant experience of consumption of alcohol, in the end, leads to a dependence to this drug (Uzun, 2003). 
Tylor et al. (1997) believed that people with alexithymia might, in an effort to get rid of their negative feelings, react through actions such as eating, using drugs, and doing involuntary behavior. They also believed that defect in the self-regulation of emotions would explain association of alexithymia with eating disorders, drug abuse, impulsive behaviors, and pathological gambling. Some researchers believe that these people use alcohol and drugs to cope with stress or improve their interpersonal performance that could possibly explain the increasing severity of substance use disorders in people with alexithymia (Thorberg et al., 2011; Cecero and Holmstrom, 1997).

Other findings showed a significant negative relationship between self-efficacy and vulnerability to addiction, and at the same time, self-efficacy was a predictor of vulnerability to addiction. These findings are consistent with the findings of Dolan et al. (2008); McKellar, Erice, Carver (2008); Sterling et al. (2007); Tate et al. (2008); and Bahadori, Khanjani (2013) indicating that people with low self-efficacy further tend to drugs. Based on these results, people with clear, well-defined, coordinated, and almost stable self-efficacy, possess greater psychological health. Thus, there is little chance that they solve their problems by using abnormal and unhealthy ways such as substance abuse.

Based on these findings, during adverse and stressful events, people with high self-efficacy show more stability and do not accept negative thoughts about themselves and their abilities. Accordingly, self-efficacy help them resist peer pressure and control their behaviors (Kiamarsi, Abolgasemi, 2012).

On the other hand, people with low self-efficacy easily believe that their conduct is useless. They quickly become frustrated, while people with high self-efficacy overcome barriers with their perseverance and self-management skills and resist in the face of problems. They have more control over their behaviors, and experience less uncertainty. Therefore, self-efficacy can improve the healthy behaviors and prevent the tendency of people to drug abuse (Bandura, 2004). In general, low self-efficacy and alexithymia can be two factors responsible for the tendency of young people to drug abuse.

This study has theoretical and practical implications. At practical level, the results of research can be used by psychologists and psychiatrists to prevent addiction and reduce its harms. In primary prevention, by using questionnaires in schools, they can identify those at risk of addiction and reduce the risk of addiction with special programs about learning the skills of self-efficacy and alexithymia. With regard to the theoretical implications, it presents new ideas and assumptions about the predictors of vulnerability to addiction. These forecasts (self-efficacy and alexithymia) not only enrich theoretical models of addiction but also strengthen the relations between the three theories of self-efficacy, alexithymia, and addiction.

The population and sample size pose some limitations on the findings, their interpretations, and attributions of cognitive variables that should be considered. Also this study was conducted only on male students and the results are not generalizable to the female population.

Based on study results, it is recommended that vulnerable students be referred to counseling centers for educational and psychological advice; drug refusal skills be trained, self-efficacy teaching methods be included in school curricula; training programs be developed to regulate and control emotions; and similar studies in other geographic areas, basic education, and education sectors and on girls be conducted.

\section{Acknowledgments}

The current research hasn't received any financial support.

\section{Conflict of Interest}

The authors declared no conflict of interests.

\section{References}

Amani, F., Sadeghiyeh Ahari, S., Mohammadi, S., \& Azami, A. (2005). [Pattern of changes in drug addicts referring to addiction centers, 1998-2003 (Persian)]. Journal of Ardabil University of Medical Sciences, 5(3), 220-4.

Ameri, F., Bayat, B., \& Khosravi, Z. (2014). Comparison of early maladaptive schemas and defense styles in asthmatic, alexithymic and normal subjects. Practice in Clinical Psychology, 2(1), 51-57.

Bagby, R. M., Parker, J. D., \& Taylor, G. J. (1994). The twentyitem Toronto Alexithymia Scale-I. Item selection and crossvalidation of the factor structure. Journal of Psychosomatic Research, 38(1), 23-32. doi: 10.1016/0022-3999(94)90005-1

Bagheri, M., Nabavi, A., Moltafet, H., \& Nagipour, F., (2010). [The study of effective factors on addiction phenomenon in the City of Ahwaz (Persian)]. Journal of Applied Sociology. 21(2), 119-136.

Bandura, A. (1993). Perceived self-efficacy in cognitive development and functioning. Educational Psychologist, 28(2), 117-148. doi: $10.1207 /$ s15326985ep2802_3 
Bandura, A. (2004). Health promotion by social cognitive means. Health Education \& Behavior, 31(2), 143-164. doi $10.1177 / 1090198104263660$

Besharat, M. A. (2007). Reliability and factorial validity of a Farsi version of the 20-item Toronto Alexithymia Scale with a sample of Iranian students. Psychological reports, 101(5), 209-220. doi: $10.2466 /$ pr0.101.5.209-220

Bahadori, Kh. J., \& Khanjani, Z. (2014). [Relationship of coping strategies and self-efficacy with substance abuse tendency among students (Persian)]. Journal of Knowledge \& Research in Applied Psychology, 14(3), 80-90.

Berenbaum, H. \& Prince, J. D. (1994). Alexithymia and the interpretation of emo-tion-relevant information. Cognitive Emotion 8(4), 231-244. doi: 10.1080/02699939408408939

Besharat, M. A., Noorbakhsh, S. N., \& Rostami, R. (2014). [Moderating Role of alexithymia in the relationship between attachment style and the severity of substance use disorders (Persian)]. Journal of Modern Psychological Research, 33, 25-50.

Birt, M. A., Sandor, V., Vaida, A., \& Birt, M. E. (2008). Alexithymia, a risk factor in alcohol addiction? A brief research report on Romanian population. Journal of Evidence-Based Psychotherapies, 8(2), 217-225.

Cecero, J. J., \& Holmstrom, R. W. (1997). Alexithymia and affect pathology among adult male alcoholics. Journal of Clinical Psychology, 53(3), 201-208. doi: 10.1002/(sici)10974679(199704)53:3<201::aid-jclp2>3.0.co;2-u

Cleland, C., Magura, S., Foote, J., Rosenblum, A., \& Kosanke, N. (2005). Psychometric properties of the Toronto Alexithymia Scale (TAS-20) for substance users. Journal of psychosomatic research, 58(3), 299-306. doi: 10.1016/j.jpsychores.2004.11.002

Dehkordian, P., Delavar, A., Jali, H, R., (2011). [Construction and standardization of diagnostic tests among students at risk of drug use in public universities in Tehran (Persian)]. Journal of Educational Measurement, 2(6):89-110.

De Rick, A. \&Vanheule, S. (2006). The relationship between perceived parenting, adult attachment style and alexithymia in alcoholic inpatients. Addictive Behaviors, 31(7):1265-70. doi: 10.1016/j.addbeh.2005.08.010

Dolan, S. L., Martin, R. A., \& Rohsenow, D. J. (2008). Self-efficacy for cocaine abstinence: Pretreatment correlates and relationship to outcomes. Psychology of Addictive Behaviors, 33(5), 675688. doi: 10.1016/j.addbeh.2007.12.001

Dolatshahi, B., Abasi, I., \& Pahlavani, H. (2016). Prevalence of high risk behaviors among women in Tehran. Practice in Clinical Psychology, 4(2), 105-112. doi: 10.15412/j.jpcp.06040205

El Rasheed, A. H. (2001). Alexithymia in Egyptian substance abusers. Substance Abuse, 22(1), 11-21. doi: $10.1080 / 08897070109511442$

Evren, C., Sar, V., Evren, B., Semiz, U., Dalbudak, E., \& Cakmak, D. (2008). Dissociation and alexithymia among men with alcoholism. Psychiatry and Clinical Neurosciences, 62(1), 40-47. doi: 10.1111/j.1440-1819.2007.01775.x

Hashemi, T., Khalilzade, S., Mashinchi, N, (2013). [Gender, comparison of alexithymia and theory of mind in university students (Persian)]. Journal of Social Cognition, 1(2), 6-13.
Hatami, F., Ghahremani, L., Kaveh, M. H., \& Keshavarzi, S, (2016). The effect of self-awareness training with painting on self-efficacy among orphaned adolescents. Practice in Clinical Psychology, 4(2), 89-96. doi: 10.15412/j.jpcp.06040203

Haviland, M. G., Shaw, D. G., Cummings, M. A., \& MacMurray, J. P. (1988). Alexithymia: subscales and relationship to depression. Psychotherapy and Psychosomatics, 50(3), 164-170. doi: $10.1159 / 000288115$

Ghadiri Sourman Abadi, F., Abdolmohamadi, K., Babapour Kheiradin, J., \& Roodsari, A. B. (2015). Prediction of alexithymia on the basis of attachment style and early maladaptive Schemas in University Students. Journal of Practice in Clinical Psychology, 3(1), 39-46.

Ghadiri Sourman Abadi, F., Sabouri, M. H., Babapour, Kh. J. (2014). Prediction of vulnerability to addiction on the basis of psychosocial stressors. Journal of Practice in clinical psychology. 2(4).239-298.

Gunzelmann, T., Kopfer, J., \& Brahler, E. (2002). Alexithymia in the elderly general population. Comprehensive Psychiatry, 43(1), 74-80. doi: 10.1053/comp.2002.29855

Karkhi M.(2012). [Wrong beliefs in addiction (Persian)] (1st ed.). Qom: Qom University of Medical Sciences.

Kiamarsi,A., \& Abolghasemi,A. (2012). [The relationship of selfefficacy, sensation seeking and coping strategies with aptitude of substance use in university students (Persian)]. Journal of Research on Addiction, 5(20), 7-24

Loas, G., Fremaux, D., Otmani, O., Lecercle, C., \& Delahousse J. (1997). Is alexithymia a negative factor for maintaining abstinence? A follow-up study. Comprehensive Psychiatry, 38(5), 296-9. doi: 10.1016/s0010-440x(97)90063-8

McKellar, J., Ilgen, M., Moos, B. S., Moos, R. (2008). Predictors of changes in alcohol-related self-efficacy over 16 years. Journal of Substance Abuse Treatment, 35(2), 148-55. doi: 10.1016/j jsat.2007.09.003

Mohamadkhani, Sh., Jazayeri, A., Mohamadkhani, P., Rafiee, H., \& Ghazi Tabatabaee, M. (2007). [Direct and indirect impact of attitude, locus of control, self-management skills and social commences on drug use among at risk adolescents (Persian)] Journal of Contemporary Psychology, 2(1), 3-12.

Nezami, E., Schwarzer, R., \& Jerusalem, M. (1996). Persian Adaptation (Farsi) of the Gene Self-Efficacy Scale. Retrieved from http://userpage.fu-berlin.de/ health/persean.htm.

Pinard, L., Negrete, J. C., Annable, L., \& Audet, N. (1996). Alexithymia in substance abusers. The American Journal on Addictions, 5(1), 32-39. doi: 10.1111/j.1521-0391.1996.tb00281.x

Rajabi, GH.R. (2006).[Evaluate the reliability and validity of selfefficacy scale in students (Persian)]. Journal of New Thoughts on Education, 2(1, 2), 111-21.

Rybakowski, J., Ziółkowski, M., Zasadzka, T., \& Brzeziński, R. (1988). High prevalence of alexithymia in male patients with alcohol dependence. Drug and Alcohol Dependence, 21(2), 133136. doi: $10.1016 / 0376-8716(88) 90058-0$

Sabouri Moghadam, H., \& Babapur Kheiradin, J. (2014). Prediction of vulnerability to addiction on the basis of psychosocial stressors. Journal of Practice in Clinical Psychology, 2(4), 271-6. 
Schultz, D., \& Schultz, S. (2000). [Theories of personality (Persian trans.)]. ( $6^{\text {th }}$ ed.). Tehran: Virayesh Publication.

Sterling, K. L., Diamond, P. M., Mullen, P. D., Pallonen, U., Ford, K. H., \& McAlister, A. L. (2007). Smoking-related selfefficacy, beliefs, and intention: Assessing factorial validity and structural relationships in $9^{\text {th }}-12^{\text {th }}$ grade current smokers. Psychology of Addictive Behaviors, 32(9), 1863-76. doi: 10.1016/j. addbeh.2006.12.018

Tate, S. R., Wu, J., McQuaid, J. R., Cummins, K., Shriver, C., \& Krenek, M., et al. (2008). Comorbidity of substance dependence and depression: role of life stress and self-efficacy in sustaining abstinence. Psychology of Addictive Behaviors, 22(1), 47-57. doi: 10.1037/0893-164x.22.1.47

Taylor, G. J., Bagby, R. M., \& Parker, J. D. A. (1997). The development and regulation of affects: Disorders of affect regulation. Cambridge: Cambridge University Press. doi: 10.1017/ cbo9780511526831.004

Tavousi, M., Montazeri, A., Taremian, F., Hajizade, E., Heidarnia,A., (2011), [Factors associated with substance abuse in adolescents by using the theory of planned behavior (Persian)]. Journal of Social Welfare Quartery. 12(44), 93-110.

Thorberg, F. A., Young, R. M., Sullivan, K. A., \& Lyvers, M. (2009). Alexithymia and alcohol use disorders: a critical review. Psychology of Addictive Behaviors, 34(3), 237-45. doi: 10.1016/j.addbeh.2008.10.016

Thorberg, F. A., Young, R. M., Sullivan, K. A., Lyvers, M., Connor, J. P., \& Feeney, G. F. (2011). Alexithymia, craving and attachment in a heavy drinking population. Psychology of Addictive Behaviors, 36(4), 427-30. doi: 10.1016/j.addbeh.2010.12.016

Uzun, Ö. (2003). Alexithymia in male alcoholics: Study in a Turkish sample. Comprehensive Psychiatry, 44(4), 349-52. doi: 10.1016/s0010-440x(03)00009-9 




October 2016, Volume 4, Number 4 